\title{
Modification of the Short-range Rocket Target RT-400 for Middle- Range Air Defence Systems
}

\author{
Hari Prasanna MANIMARAN ${ }^{1}$, Algimantas FEDARAVICIUS ${ }^{2}$ \\ ${ }^{1,2}$ Department of mechanical engineering, Kaunas University of the technology, K. Donelaicio St.73, LT-44249, \\ Kaunas, Lithuania,
}

E-mails: ${ }^{1}$ hariprasanna.manimaran@gmail.com; ${ }^{2}$ algimantas.fedaravicius@ktu.lt

\begin{abstract}
The objective of the research is to analyze the external ballistic characteristics of middle-range rocket target with a constant thrust and varying rocket motor operating time. The main requirement is to achieve the rocket target with horizontal distance (range) of $20 \mathrm{~km}$ and vertical distance (altitude) of $10 \mathrm{~km}$. The rocket motor to be used should be RM-12K designed and built by the Kaunas University of Technology, Institute of Defence technology. This motor can produce up to $12 \mathrm{kN}$ thrust for 3.2 seconds. To achieve the goal, a computational model is designed and numerical modelling for ballistic analysis is carried out. In this research, two different configurations are used to achieve the requirement. In the first test, all four motors are ignited together for 3.2 seconds which produce $48 \mathrm{kN}$ thrust force. In third configuration two motors are used for 3.2 seconds to produce $24 \mathrm{kN}$ and after the burnout, the second two motor is ignited for 3.2 seconds. Comparative analysis of two different configuration shows that the requirement of $20 \mathrm{~km}$ range and $10 \mathrm{~km}$ altitude was realised by using two plus two motors for 6.4 seconds of operational time.
\end{abstract}

KEYWORDS: solid-propellant rocket motor, external ballistics, flight range, velocity, acceleration, thrust impulse, rocket target.

\section{Introduction}

As defence technology is rapidly growing, it requires effective training to operate the defence hardware. Live firing exercise are mostly conducted to test the specific military equipment such as weapon systems. During the practice, personnel requires a target that imitates real incoming enemy military hardware is required. It demonstrates the realistic scenario for the trainee to acquaint with the battle situation. More precise practise making the personnel a skilful operator. For this purpose, targets that resemble enemy aircraft or rocket are used. Initially, the practice is limited to virtual and dummy targets. Targets are of different types based on the requirements. The main objective of targets is to be used as a bullseye target for practice. Most of the targets are designed to be destroyed during the exercise. Targets may be used in land, sea and air defence.

Most of the developed countries have designed their own targets for their personnel. Targets are three types as stationary, UAV, rocket target. Some targets are turbojet engine powered drones and missile targets. These are mostly made from the missile parts without warheads. Other designs are particularly designed to meet the demand. As the drone targets are used to resemble as low-speed vehicles like spy planes, unmanned aerial vehicle and subsonic missiles. These drones cannot simulate the situation for fast-moving missile and fighter aircraft. To fulfil this requirement rocket target are used. These target use rocket motor, mostly solid propellant.

Rocket target usually slower than the real missile or aerial vehicle which is used to shoot the target. This is because, the trainee personnel require training to acquire, lock and terminate target. In the early stage of the training, identifying the fast-moving object is difficult. To match the trainee reaction time, the speed of the target is decided. Rocket target is used once and mostly destroyed during the exercise unlike drones can be reused. In drones, the rocket is kept as secondary target and ejected to resemble the missile. Some drone use rocket for the first stage as rocketassisted take-off (RATO). Drone targets are difficult to maintain and cannot be operated in all-weather condition. But solid-propellant rocket target can be fuelled and stored for a longer period. And require less maintenance. In considering all the benefit of using rocket target for a military exercise, it is necessary to design and test the hardware.

\footnotetext{
${ }^{1}$ Corresponding author. Tel.: 370-6-54-33-957.

E-mail address: hariprasanna.manimaran@gmail.com
} 
In rocket target design internal and external ballistics are mainly analysed. Internal ballistics deals with the propulsion system characteristics whereas the external ballistics study about the flight of the projectile. The external ballistics of the target gives the basic parameters such as thrust, velocity, acceleration, altitude flight angles and range.

With the help of this parameter, the target can be optimised for requirements. Design can be altered to meet the required specification. In this research rocket target to be used for the air defence system is analysed. RT-400 is designed and developed by Institute of defence technology, the Kaunas University of Technology with a range of $5 \mathrm{~km}$. The range can be increased by the optimising the propulsion system. By making the alteration in any system, it is required to analyse for the performance. External ballistics is the performance of the rocket target.

Based on RT-400 with single motor data, multiple motor grid can be studied. As per the requirement, the range of the missile varies. To increase the range from short to the medium additional motor is added. In this research, the middle range rocket target with four motors will be used to achieve 15-20 km range.

\section{Basic data of the rocket target RT-400}

\subsection{Construction of the rocket target RT-400}

An RT-400 is rocket target designed and tested by the Kaunas University of Technology, Institute of defence technology, Lithuania by a research team of Prof. Algimantas fedaravicius, Arvidas Survila, and Saulius Rackauckas and used as an aerial target in various military exercise for the stringer missile system [1]. RT-400 aerial target is mostly used for the practice of air defence or anti-missile defence system in Lithuania for practice in the land as well as the navy ship [2]. Advancement of this type is being researched. Figure 1 and 2 shows computational model of RT-400.

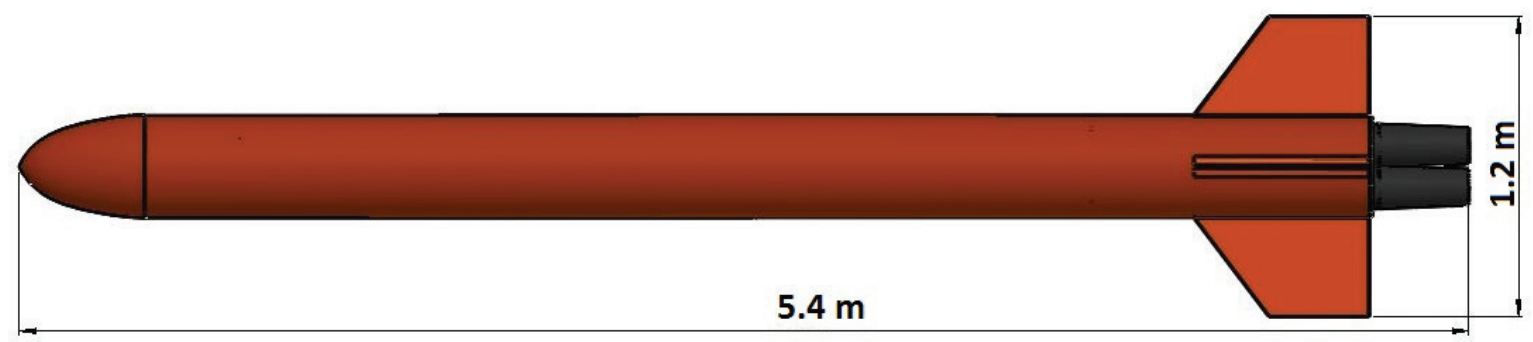

Fig. 1. Computational model of rocket target.
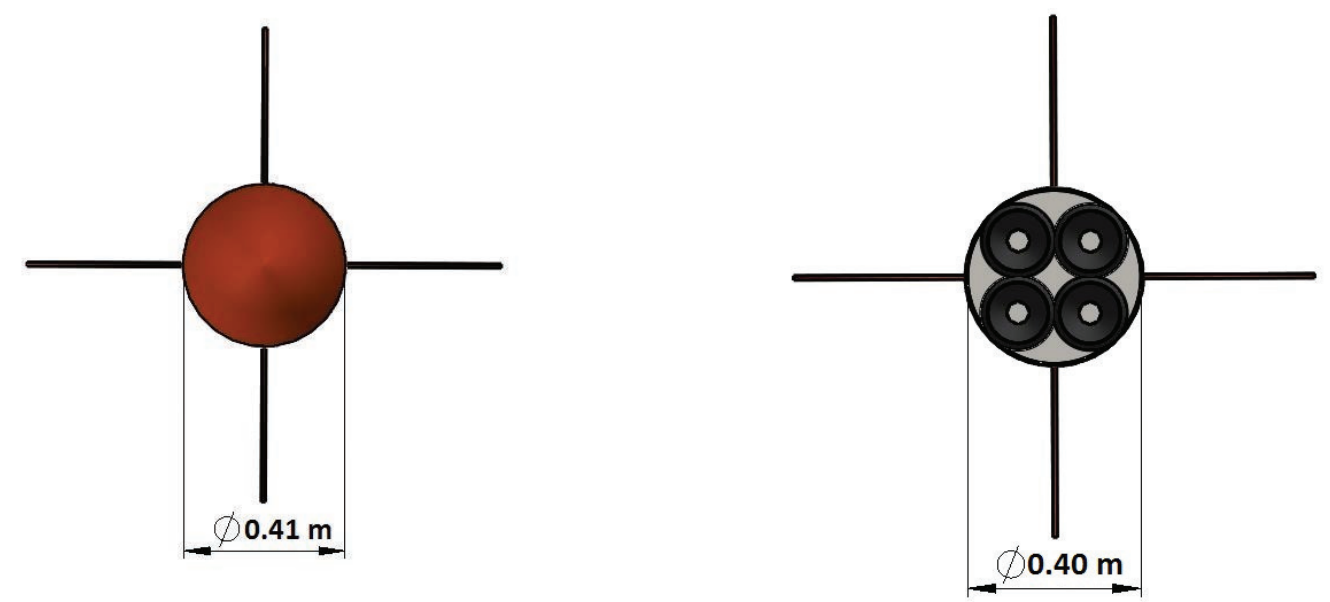

Fig. 2. Front and back view of the assembly 
Technical characteristics of the rocket target RT-400

\begin{tabular}{|c|c|c|c|c|c|}
\hline No & Property & Values & No & Property & Values \\
\hline 1. & Length of the target (m) & 5.2 & 9. & $\begin{array}{l}\text { Rocket motor mass with propellant } \\
(\mathrm{kg})\end{array}$ & 35 \\
\hline 2. & Length of the rocket motor, $(\mathrm{m})$ & 1.06 & 10. & Rocket mass $(\mathrm{kg})$ & 104 \\
\hline 3. & Diameter of the target $(\mathrm{m})$ & 0.4 & 11. & Burn time of the rocket motor (s) & 3.25 \\
\hline 4. & The diameter of the rocket motor $(\mathrm{m})$ & 0.16 & 12. & Maximum flight time of the rocket (s) & 44.92 \\
\hline 5. & $\begin{array}{l}\text { The nominal thrust of the rocket motor } \\
(\mathrm{kN})\end{array}$ & 10 & 13. & Maximum flight range $(\mathrm{km})$ & 4.5 \\
\hline 6. & The impulse of the rocket motor (s) & 32 & 14. & Maximum flight height (km) & 2.2 \\
\hline 7. & $\begin{array}{l}\text { The specific impulse of the rocket } \\
\text { motor (s) }\end{array}$ & 182 & 15. & Velocity range of the rocket $(\mathrm{m} / \mathrm{s})$ & $30-282$ \\
\hline 8. & Propellant mass $(\mathrm{kg})$ & 18 & 16. & Drag coefficient & 0.486 \\
\hline
\end{tabular}

\subsection{Technical Characteristics of the Rocket Motor RM-12K}

RT-400 is aerial target uses a single rocket motor which produces $12 \mathrm{kN}$ thrust is represented as RM-12K. The RM-12K obtain the neutral thrust and specific impulse of 182 seconds. Each motor produces 12-kilo newtons of thrust for 3.2 seconds of burn time. RT-400 obtain maximum velocity of $270 \mathrm{~m} / \mathrm{s}$ before the burnout. This gives longer flight duration. RM-12k can make RT-400 accelerate up to $120 \mathrm{~m} / \mathrm{s}$ for a period of 3.2 seconds and after burning out the acceleration reduces to a minimum and increase during the gliding stage [3].

The propellant is chosen as ammonium nitrate composite-based propellant (ANCP). A composite propellant is a solid propellant in the form of heterogeneous propellant grains composed of oxidizer crystals held together in a matrix of a synthetic or plastic binder [4].

The metal casing is designed to protect from the thermal fluxes and keep the grain in fixed with the outer structure [5]. Stainless steel is chosen for its properties against temperature and pressure to withstand the combustion [6]. The thermal protection layer is applied inside the case. The total mass of $12 \mathrm{~kg}$ for each propellant case is used.

Table 2

Nozzle data

\begin{tabular}{|l|c|c|c|c|}
\hline \multicolumn{1}{|c|}{ Nozzle section } & Diameter $(\mathbf{m})$ & Radius $(\mathbf{m})$ & Area $\left(\mathbf{m}^{2}\right)$ & Length (m) \\
\hline convergent & 0.16 & 0.08 & 0.020 & 0.05 \\
\hline throat & 0.053 & 0.027 & 0.0022 & - \\
\hline divergent & 0.15 & 0.075 & 0.0177 & 0.316 \\
\hline
\end{tabular}

\section{Design of the Rocket Target for Middle-Range Air Defence Systems}

\subsection{Construction of Middle-Range Aerial Target (4 Motors)}

This configuration will increase the range and produce symmetrical thrust force, but the total burn time will be less. The velocity gain will much higher than the other possibilities. All four motors are burned to produced maximum possible thrust and analyse the external ballistics to obtain maximum range and altitude. 


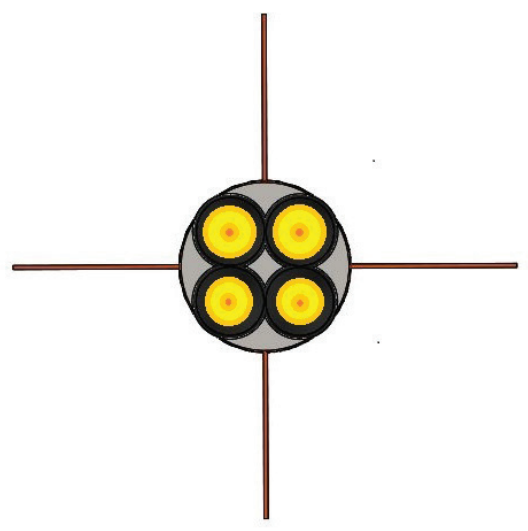

Fig. 3. Rocket with four motor thrust.

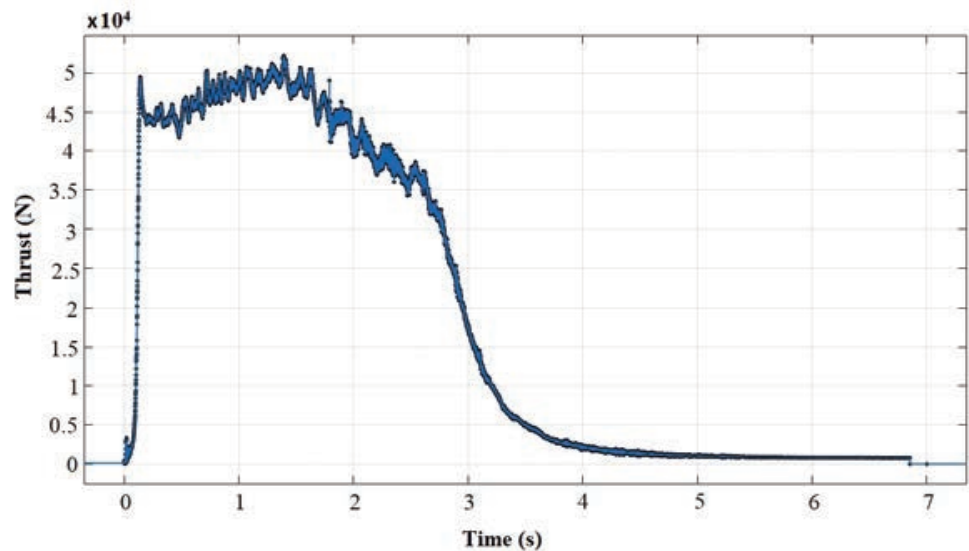

Fig.4. Thrust vs time graph for four motor.

Figure. 3 shows all motor burning rocket. Figure. 4 shows the thrust vs time graph. The total thrust of $48 \mathrm{kN}$ is produced for the 3.2 seconds and starts reducing after $3.2 \mathrm{~s}$ due to the unavailability to propellant until the grain reaches the silver.

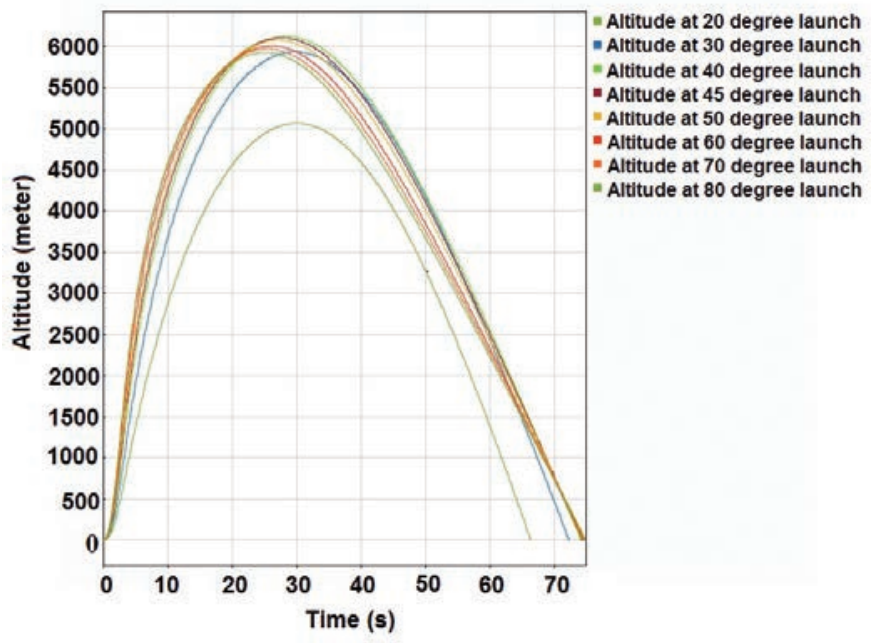

Fig. 5. Altitude vs time graph for four motor.

Figure. 5 shows altitude vs time graph. At a maximum angle of 70-degrees, the vertical forces overcome the horizontal forces and gravity to reach a maximum altitude of $6265 \mathrm{~m}$. the rocket reaches its maximum altitude at 30 seconds of flight time. Figure .6 shows altitude vs distance graph

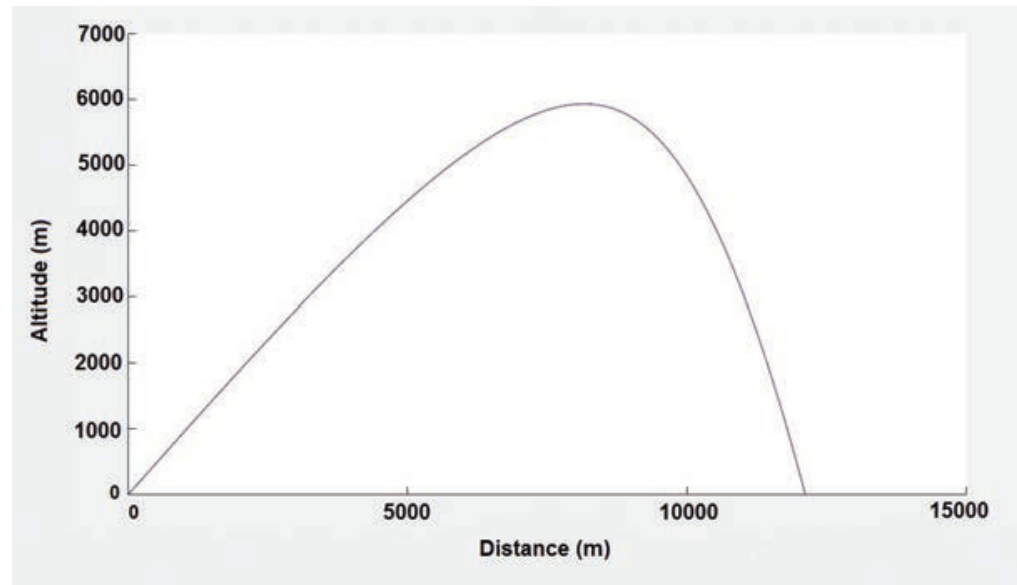

Fig. 6. Altitude vs distance graph. 
The maximum range is obtained at 50-degree launch is $12,660 \mathrm{~m}$ with an altitude of $6065 \mathrm{~m}$. The range obtained is more than 5 times the range obtained in the single motor case. This is due to the increment in the thrust and velocity.

\subsection{Numerical Modelling of the External Ballistics (2+2motors)}

Igniting the alternate motor gives symmetrical burn and increasing the total burning time give the advantage of thrust for more time. This configuration may increase the range.

has two subdivision the ignition of 2 motors for the first 3.2 seconds and remaining two more motors are ignited for another 3.2 seconds. Figure. 7 shows the sequence of burning four motors
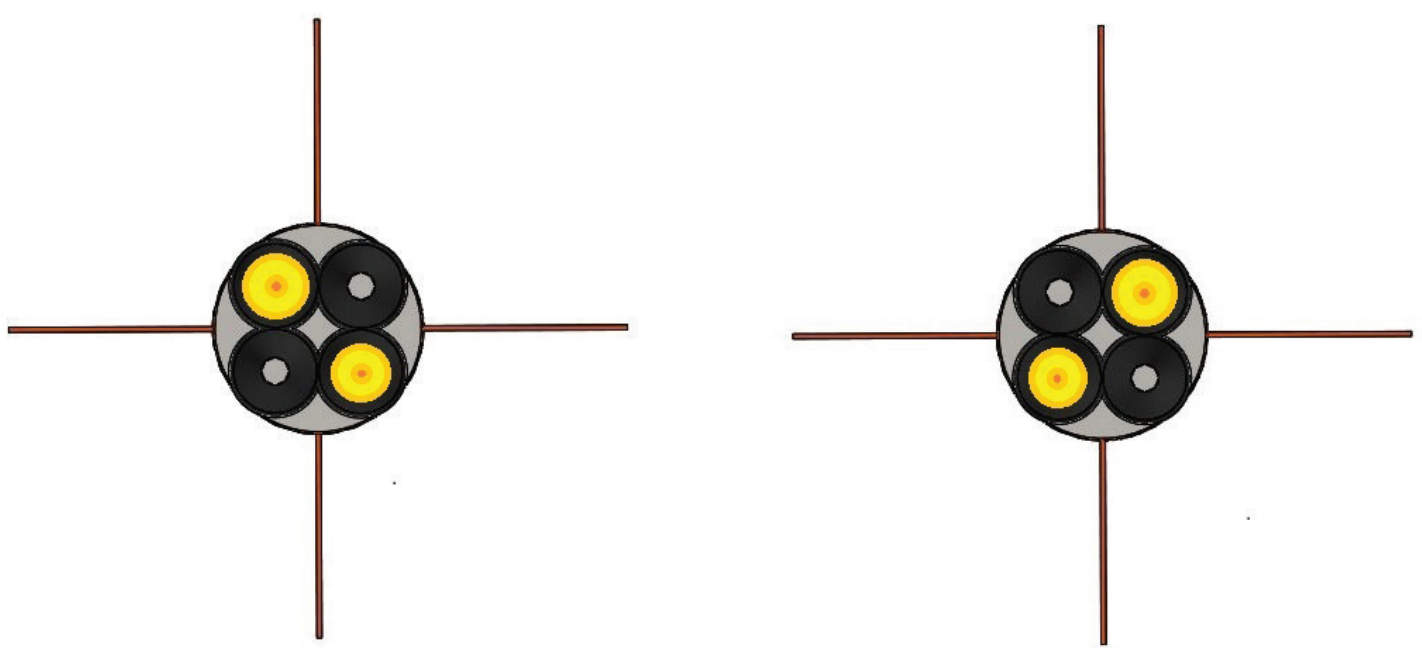

Fig. 7. Shows the Ignition of 1,3 motor and 2,4 motor.

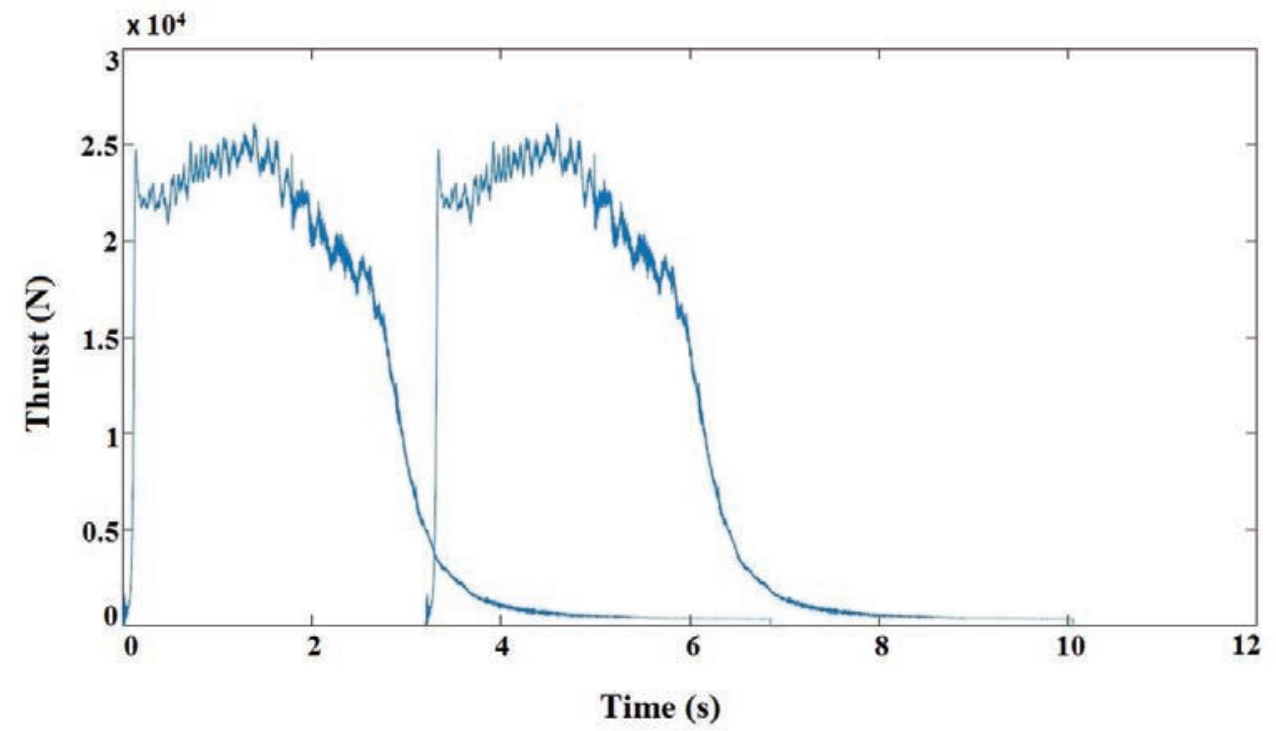

Fig. 8. Thrust vs time graph of 2 motor.

Thrust vs time graph of figure. 8 shows the increment of thrust to $24 \mathrm{kN}$ at the beginning of the burn when there is the large area of propellant is exposed to the hot gas the neutral burn progress for the period of 2.4 seconds and the total surface area exposed becomes circular, the thrust force starts falling until the burnout at 3.2 second. The initial mass of $185 \mathrm{~kg}$ and the final mass this stage is $149 \mathrm{~kg}$, the velocity is affected by this factor of change in mass. As only two motors are ignited remaining two remains intact with propellant being filled. The burning motor must produce the 
thrust to push the entire weight of the rocket body. It is obvious that the $24 \mathrm{kN}$ force generate higher velocity increment than the single motor and can reach longer distance and altitude but the comparably lower than the four motors.

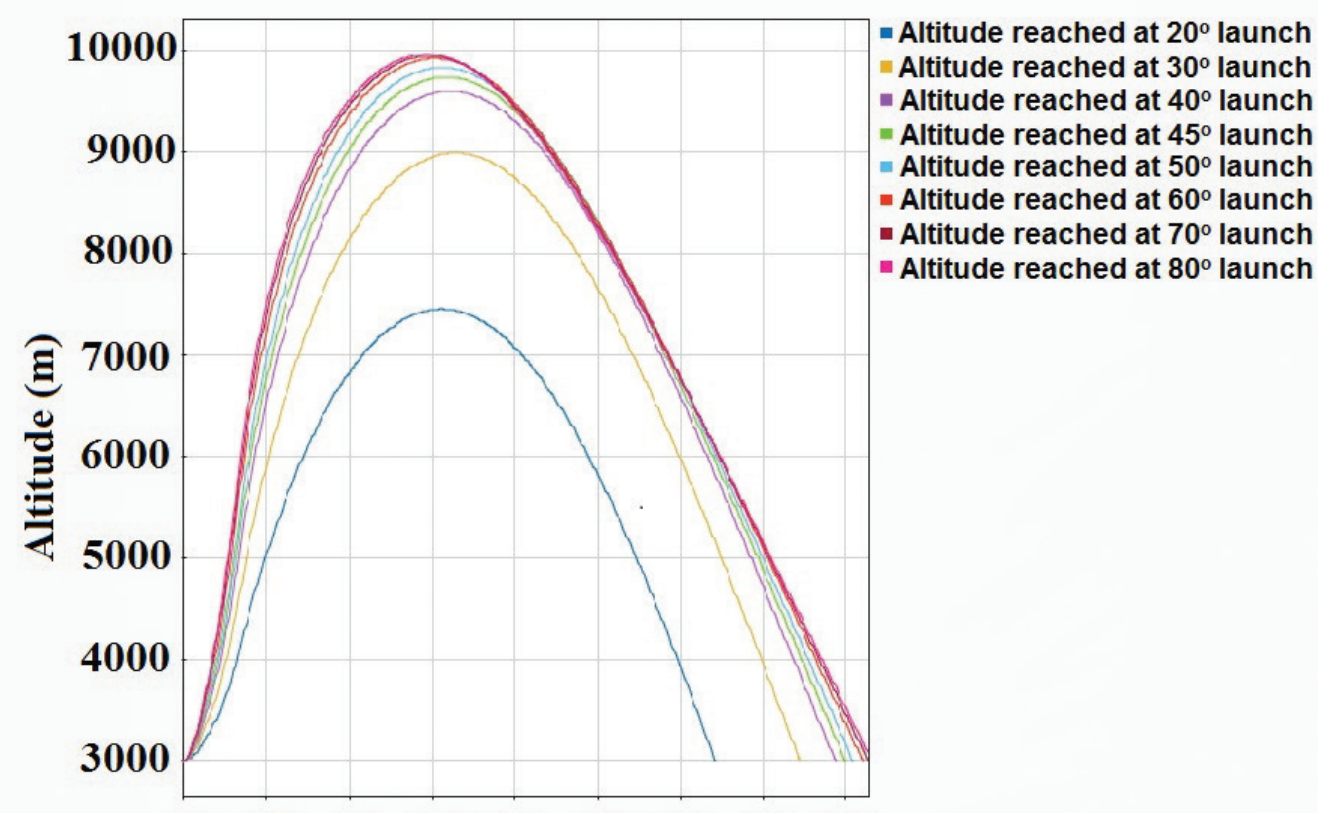

Fig. 9. Altitude vs time graph for $2+2$ motor.

Figure.9 shows, with two motor power, the rocket can travel up to the maximum of $3401 \mathrm{~m}$ at 80 -degree launch angle

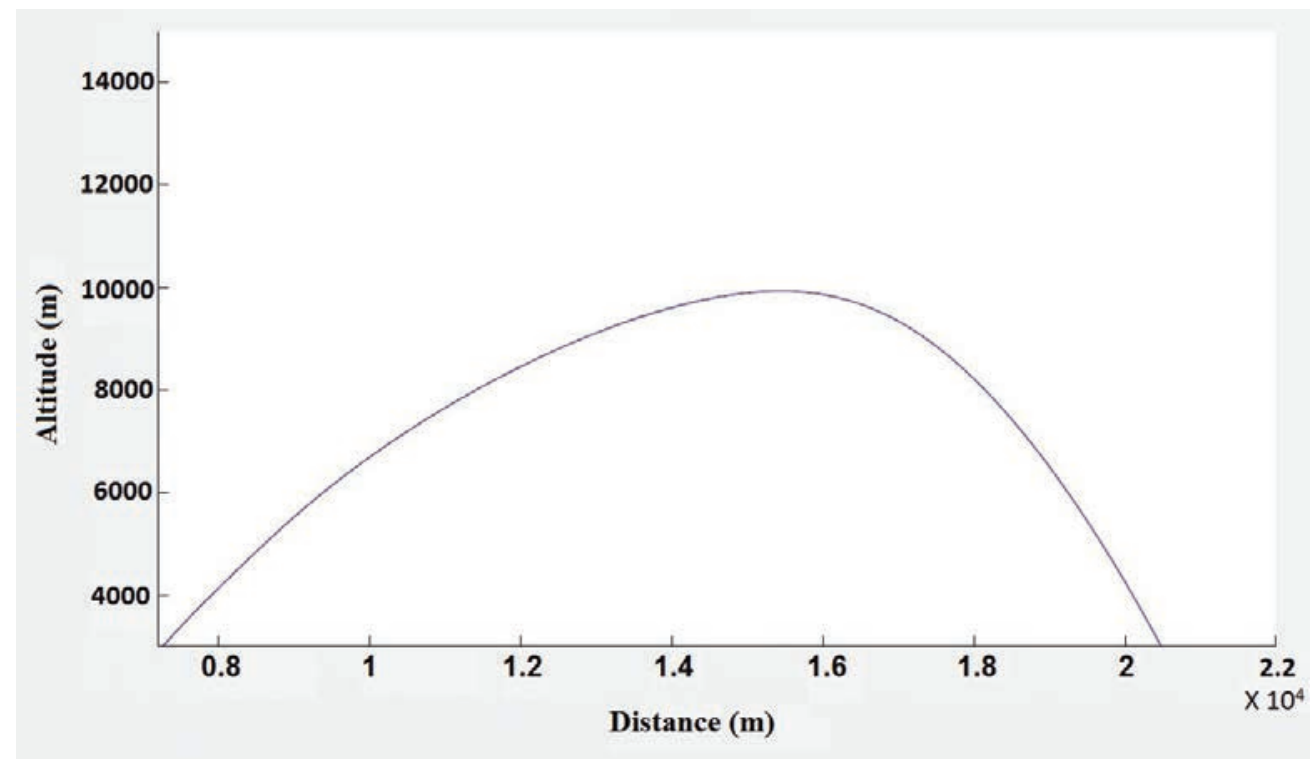

Fig. 10. Altitude vs distance graph.

Figure. 10 shows from $3000 \mathrm{~m}$ attitude and $7200 \mathrm{~m}$ distance travelled from point zero, the power from the second stage boost the rocket to the further distance of 12 kilometres. At the end of the flight, the rocket reaches $19.9 \mathrm{~km}$ distance and total altitude of $9360 \mathrm{~m}$. 


\subsection{Technical Characteristics of the Rocket Target for Middle-Range Air Defence Systems}

RT-400 is a simple design with low manufacturing cost. It can be transported and needless area for launch. It is very cost-effective and reliable rocket target. RT-400 is towed and can be transported to any location and has specially designed mobility vehicle for transportation. It can be launched at any angle as the vehicle can be lifted. Launch rod provides support to rocket body during transportation as well as during the launch. For transporting to any place, the tow vehicle is attached to an automobile.

Table 3

Comparison of results for range and altitude

\begin{tabular}{|c|c|c|c|c|c|c|}
\hline $\begin{array}{c}\text { Launch } \\
\text { angle } \\
\text { (degrees) }\end{array}$ & $\begin{array}{c}\text { The altitude of } \\
\text { a single motor } \\
(\mathbf{m})\end{array}$ & $\begin{array}{c}\text { The altitude } \\
\text { of four motors } \\
\mathbf{( m )}\end{array}$ & $\begin{array}{c}\text { The altitude } \\
\text { of } \mathbf{2}+\mathbf{2} \text { motor } \\
\mathbf{( m )}\end{array}$ & $\begin{array}{c}\text { Range of } \\
\text { single motor } \\
\mathbf{( m )}\end{array}$ & $\begin{array}{c}\text { Range of four } \\
\text { motors (m) }\end{array}$ & $\begin{array}{c}\text { Range of 2+2 } \\
\mathbf{m o t o r}(\mathbf{m})\end{array}$ \\
\hline 20 & 180 & 3275 & 2932 & 1890 & 10,280 & 14,334 \\
\hline 30 & 286 & 4928 & 5473 & 2132 & 11,240 & 17,215 \\
\hline 40 & 516 & 5743 & 7496 & 2548 & 11,870 & 18,284 \\
\hline 45 & 624 & 5927 & 8116 & 2501 & 12,120 & 19,628 \\
\hline 50 & 738 & 6065 & 8656 & 2552 & 12,360 & 19,916 \\
\hline 60 & 930 & 6195 & 8787 & 2320 & 12,660 & 18,445 \\
\hline 70 & 1019 & 6265 & 9192 & 1816 & 12,280 & 16,805 \\
\hline 80 & 1196 & 6257 & 9360 & 1012 & 9137 & 11,489 \\
\hline
\end{tabular}

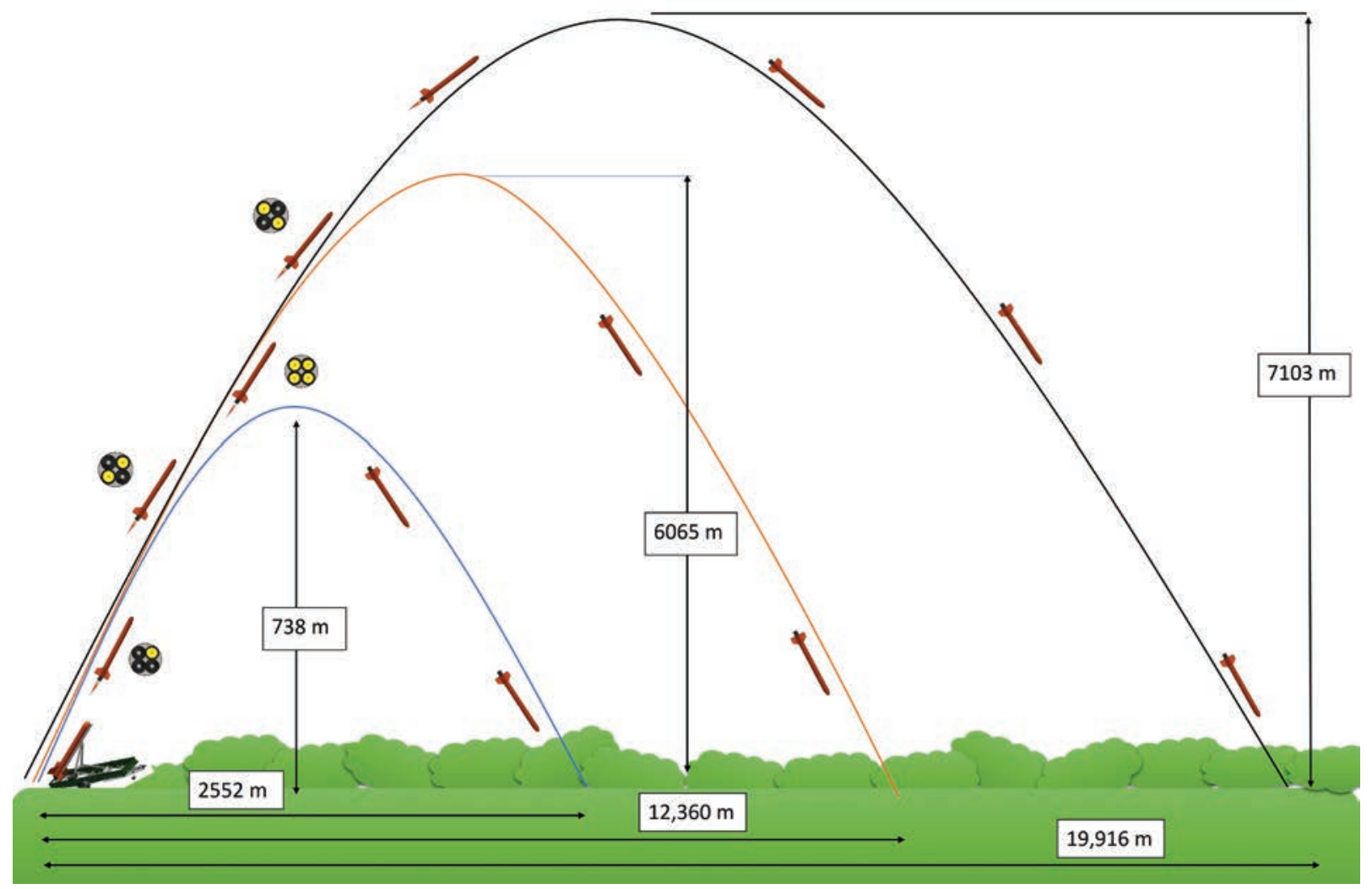

Fig. 11. Schematic of mission design. 


\section{Conclusions}

- $\quad$ engineering conception for modernisation of RT-400 as middle-range rocket target in middle range air defence systems was created;

- computational model using SolidWorks ${ }^{\circledR}$ and numerical modelling in MATLAB ${ }^{\circledR}$ was carried out;

- external ballistic parameters such as thrust, velocity, acceleration, altitude (height), range (distance), drag force, g-loads, flight angles are detailed;

- from the research of different model following results are obtained:

1. rocket burning one motor can travel up to a range of $2552 \mathrm{~m}$ with an altitude of $1196 \mathrm{~m}$;

2. four motors burning together reach a range of $12360 \mathrm{~m}$ and altitude of $6257 \mathrm{~m}$;

3. igniting two motors in the first stage and burning two more motors after burnout of first two motors can make the rocket to travel $19916 \mathrm{~m}$ with an altitude of $9360 \mathrm{~m}$.

- $\quad$ even though the magnitude of thrust output from the two-plus two-motor configuration is lower compared to the model ignites all motors in a four-motor grid of $48 \mathrm{kN}$, the advantage of continuous supply of thrust in two plus two motor model boost the second stage to maximum distance;

- from the comparative analysis, it is concluded that the rocket target with four motor grid using sequential ignition, the first stage of two motors for 3.2 seconds produce $24 \mathrm{kN}$ and igniting another two motor for 3.2 seconds with $24 \mathrm{kN}$ after the burnout of the first stage is preferred;

- four motors are arranged in a parallel configuration: alternate motors are ignited to produce symmetrical thrust which gives stable rocket flight;

- the reduction in second stage mass and initial velocity of $350 \mathrm{~m} / \mathrm{s}$ from the first stage coupled to produce a higher range for the rocket target;

- the flight velocity reaches supersonic during the flight of both four and two plus two motor configurations;

- research and comparative analysis of rocket external ballistic characteristics by constant thrust and different time impulses are completed to use the data in the modernisation of rocket target for middlerange air defence systems.

Acknowledgements. This work was supported by the Research Council of Lithuania, grant No. S-MIP-17-94 "Experimental Rocket: Research and Development".

\section{References}

1. Algimantas Fedaravičius, Saulius Račkauskas, Arvydas Survila, Aistis Šamelis, External ballistics simplified model of the "RT-400" rocket aerial target. Ryn : s.n., 2017. 11th International Armament Conference on Scientific Aspects of Armament and safety technology. 2081-5891.

2. Saulius Račkauskas, Algimantas Fedaravičius, Arvydas Survila. Numerical study on internal ballistics characteristics of a solid-propellant rocket motor. Kaunas : s.n., 2019, Journal of Mechanika, Vol. 2. 1392-1207.

3. Saulius Račkauskas, Algimantas Fedaravičius, Arvydas Survila, Laima Patasiene, Design of the testing system for solid propellant rocket motor thrust measurements using mathematical modelling techniques, 2015 , JVE International Ltd, 2424-4635.

4. George P. Sutton, Oscar Biblars. Rocket propulsion elements. seventh. New York : John Wiley \& Sons, Inc, 2001. 0-471-32642-9.

5. Davenas, Alain. Solid rocket propulsion technology. 1993, New York : Pergamon Press. 0-08-040999-7.

6. Taylor, Travis S. Introduction to rocket science and engineering, 2009, London : CRC-Press.

7. O. John.A.Lukacs, “Trajectory-Shape-Varying Missile Guidance for Interception of Ballistic Missiles during the Boost Phase", 23 august 2007, AIAA Guidance, Navigation and Control Conference and exhibit. 